\title{
Berkeley computer sleuth outwits West German hacker
}

\section{Munich}

Researchers at Lawrence Berkeley Laboratories (LBL) in California tracked an intruder in their computer system for almost a year as he sifted through hundreds of US systems seeking classified data. The intruder was finally located in West Germany, but prosecution has foundered for lack of evidence, although the FBI is still looking into the possibility of espionage

The incident has revealed weak points in computer operating systems and security procedures as well as in West German law on computer espionage. But by treating their investigation as a "valuable research project", Berkeley astronomer Clifford Stoll and his colleagues have gained experience of tracing 'hackers' which may help prevent future break-ins.

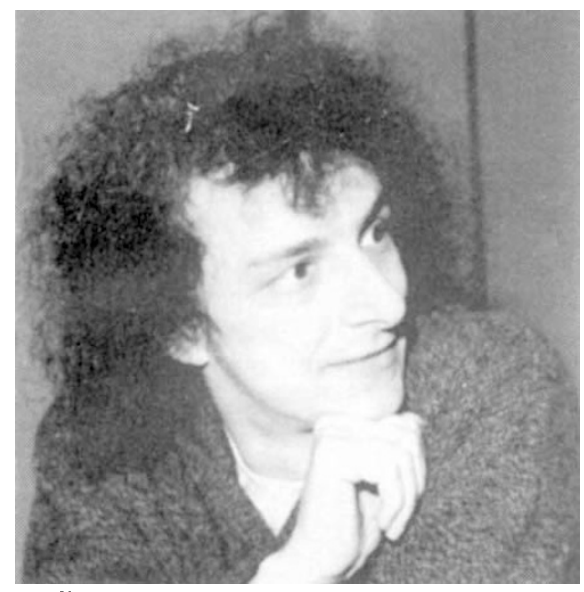

Stoll-investigating computer espionage.

Stoll first detected the intruder in August 1986 when a discrepancy arose in the LBL computer's internal accounting records. Soon afterwards, the National Computer Security Center (NCSC) at Fort Mead, Maryland, notified LBL that someone using an LBL account had tried to access its computer, which turned out to be the same person.

LBL is thought to have been the target because of its proximity, in name and location, to Lawrence Livermore Laboratories, where classified defence projects are carried out. LBL does no classified research. Stoll, at first believing the intruder to be a Berkeley student, spent ten months tracing the hacker to Hannover, West Germany, in June last year.

The hacker had tried to gain access to about 450 computer systems in the United States, Japan and West Germany, most of them used for military work. Operating systems breached included AT\&T's UNIX, Digital Equipment's VMS and International Business Machines, VM-TSO. In total, the intruder breached more than 30 of the systems, but Stoll says that LBL researchers monitored "every keystroke", notifying the violated systems of the intrusions.

The eventual give-away was the communications delay. Working with US and West German authorities, Stoll laid a trap using made-up data about the US Strategic Defense Initiative (SDI). The intruder took the bait in June 1987, staying connected with the LBL computer for over an hour - long enough for the West German authorities to trace and arrest him.

An account of Stoll's project has been published in the May issue of Communications of the Association for Computer Machinery, a respected computer science journal, which blames sloppy security procedures for many of the break-ins.

But the case against the alleged hacker has had to be dropped because he was not caught in the act. A local court found that the telephone trace back to his apartment was insufficient evidence to prove he had been the culprit. West German authorities returned the suspect's confiscated computer and memory diskettes unread because they never received the court's permission to check for the LBL files

Bremen public prosecutor Hans-Georg von Bock und Polach says that officials hands are tied in part hecause merely entering a computer system is not illegal in West Germany. Authorities could have gained access to data coming over the telephone with a wiretap, but such a procedure would only have been approved if national security - of either West Germany or the United States - had been thought to be at risk.

The continuing FBI investigation has been triggered by a letter to Stoll from Pittsburgh enquiring about some of the material in the trumped-up SDI file; the author identified himself as an "international arms dealer"

Stoll says that the implications of the case for open international computer networks are dire, remarking that funding agencies have already eliminated some international links because of break-ins.

Steven Dickman

\section{Top French mathematician turns down lucrative Crafoord prize}

\section{Paris}

FrenCH mathematician Alexander Grothendieck, whose revolutionary work in algebraic geometry won him the Fields medal in 1966, has turned down the Crafoord prize he was to share with his former student, Pierre Deligne. In his letter to the Swedish Royal Academy of Sciences published in the French newspaper Le Monde on 4 May, Grothendieck not only questions the justification for lucrative honours but also attacks the morality of contemporary mathematics.

Grothendieck, who is due to retire in October from his post at the University of Montpelier, is regarded highly by his colleagues. But, according to Deligne - who has accepted the award - the snub comes as no surprise. "He is a very obstinate man. When he was awarded the Fields medal, he did not go to Moscow to receive it."

Since 1970, Grothendieck has withdrawn from active research. His outspoken views on world ecology have subjected him to ridicule, especially after a stormy period at the Collège de France when his non-mathematical preoccupations disappointed those who had nominated him. This withdrawal has apparently led to the disillusion principally behind his decision not to accept the Crafoord prize

"In the past two decades", he says "the ethics of the scientific milieu (at least as far as mathematics is concerned) have decayed to the point where pillage, pure and simple, between colleagues (especi- ally at the cost of those least able to defend themselves) has become almost the general rule. In any case it is tolerated by all, even in the most flagrant and iniquitous cases."

He also feels that such awards serve no useful purpose: "fertility is rewarded by progeny, not by honours". Even the financial reward - the Crafoord prize is worth $\$ 270,000$ - is unnecessary, he says. Such prizes are usually awarded to high-level researchers who already have "material well-being and scientific prestige".

The publication of Grothendieck's letter has taken the French mathematics community by surprise, even if his views are well known. Fearful that the frank rebuttal will displease the Swedish Royal Academy, leading mathematicians are seeking a representative to apologise.

But Pierre Deligne feels the attack will have little real impact on international mathematics. "Of course plagiarism exists within mathematics, but probably less so than in other fields of science. Sometimes, when a result has been found, the author feels no need to publish". Another former colleague, Jean-Pierre Ferrier, shares this view, "Grothendieck is a man of extraordinary generosity and has left a permanent mark both on mathematics and his students. But his view of scientific research has always been idealistic. The reality of competitiveness was always there, but perhaps it is only now that he sees it"

Peter Coles 